\title{
Morbid Motion Monitor
}

\author{
Mohammad Reza Dawoudi* \\ Salo Nursing Campus, Turku University of Applied Sciences, Finland
}

Submission: June 10, 2017; Published: August 11, 2017

*Corresponding author: Mohammad Reza Dawoudi, Salo Nursing Campus, Turku University of Applied Sciences, Finland, Email: mrdawoud@abo.fi

\begin{abstract}
Adequate pain assessment is critical for evaluating the efficacy of analgesic (pain-killing drugs) treatment in clinical practice and during the development of new therapies [1]. Healthcare providers frequently lack the knowledge and skills to provide optimal pain management for cancer survivors [2]. However, with the increasing rate of morbid cancers, several methods for evaluating of chronic pain are suggested. Motion of morbid has been defined as the rate of pine and it is linked with various co-morbid conditions. In this project we describe a novel technique for monitory morbid motion using match technique based on DNA modeling. This model takes into account textual and visual contents to measure the similarity between the frames of videos data which are generated in hospital. We have developed a novel tool for the assessment of chronic pain by standardized motion rate of morbid on bedside.
\end{abstract}

Keywords: Pain assessment; Image processing; DNA modeling; Data collection

\section{Introduction}

It is widely accepted that the motion in cancer survivors during treatments are the result of neuropathic pain. In the last few years much research has been undertaken to develop screening tools for evaluating of chronic pain. One of the current screening tools for neuropathic pain is called "Leeds Assessment of Neuropathic Symptoms and Signs (LANSS). The Leeds assessment of neuropathic symptoms and signs (LANSS) Pain Scale is based on analysis of sensory description and bedside examination of sensory dysfunction, and provides immediate information in clinical settings [3]. It may be used for the initial screening of neuropathic pain patients. The Neuropathic Pain Questionnaire (NPQ) is another initial screening tool, which has the ability to provide a quantitative measure for the descriptors important in the diagnosis and assessment of neuropathic pain [4].

Galer and Jensen have shown NPS scores are changed in response to treatments [5]. Douleur Neuropathique en 4 questions (DN4) is another tool in order to use in clinical and research settings. It was developed by the French Neuropathic Pain Group and has ability to ability to distinguish nociceptive from neuropathic pain [6]. Nociceptive and neuropathic components require different pain management strategies. In 2005, Freynhagen et al. [7] published the screening tool referred to as pain DETECT, which was developed and validated in cooperation with the German Research Network on Neuropathic Pain [8]. These tools are based on verbal pain description with, or without, limited bedside testing. The clinical utilization of these tools can provide an approach to characterizing the complexity of assessment. These tools are designed to investigate the factors which may underlie patients' descriptions of their own pain, whiles our system is designed to analyze adjectives which may underlie doctor's descriptions of patient pain. To solve the verbal pain description problems and reach to underlie doctor's descriptions, a new system call, Morbid Motion Monitor is proposed. This method is based on "Texture Analysis using DNA Modelization method".

\section{This system is included in three steps}

Data collection: Primary, information is collected to provide data regarding storing, analysis and presentation. These data generated by the hospital on the basis of video data monitoring indicators for the period of bedside. In second step this video data is separated frame by frame.

Present finding: A quality analysis of the data is performed using Texture analysis based on DNA Modeling. DNA Modeling of data is an arrangement for allowing numbers of pixels values and pixel maps to be presented as a sequence of characters. In this system every pixel value is coded by four characters. Statistical inference methods are used to detect similarities in sequence of characters.

Data export: There are systems that provide data export into available patient files or any systems for verification of data. 
A general framework for document Morbid Motion Monitor is presented in Figure 1.

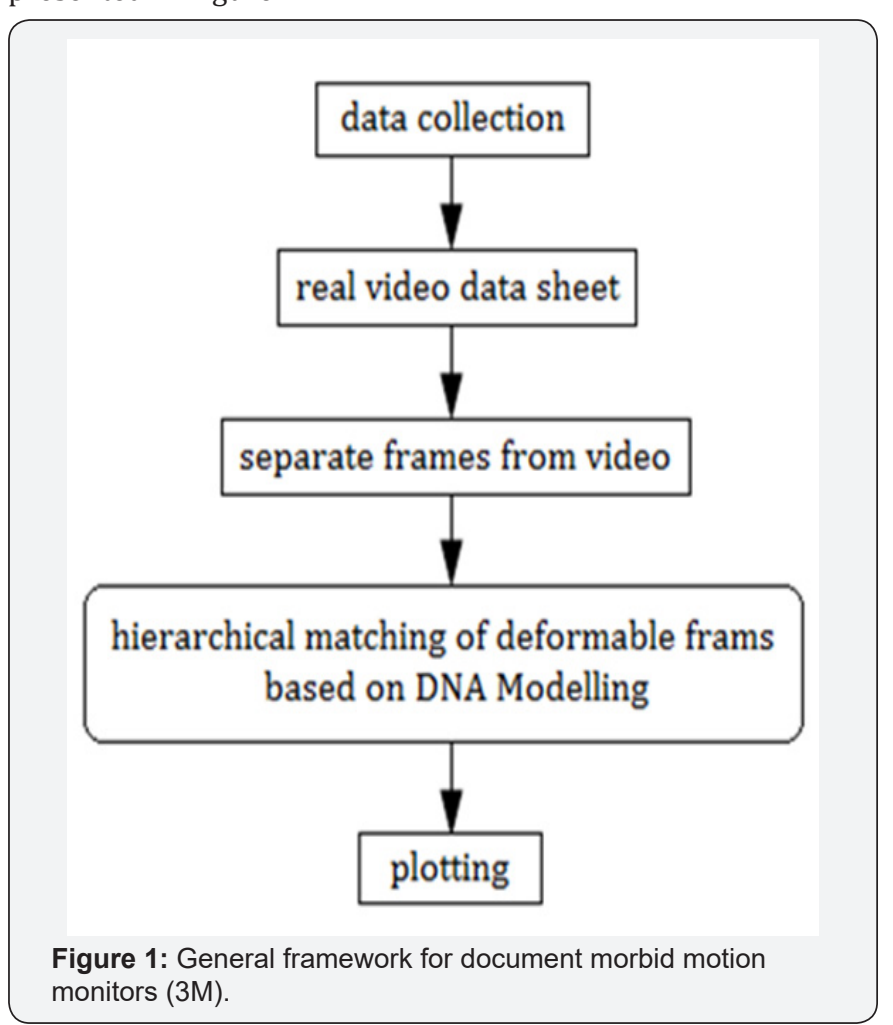

\section{Methods and Materials}

The data which is generated by the hospital on the basis of video data recorder is separated frame by frame. This execution is done by Separating Video Frames tools (e.g. Video to JPG Converter, A4 Image Video Converter,). The next set of function is about the visual differences between various frames. A variety of techniques can be used as a basis for comparison between frames. One of these techniques is called Texture analysis based on DNA Modeling. The method is based on the linear mapping and the one-to-one correspondences between point features extracted from the frames and on calculating similarities in pixel values. This correspondence is determined by comparing two strings constructed from pixel values of the frames.

The method uses a table called the Quarter Code table, which is the set of characters and numbers. In this table every number between 0 and 255 is translated into a unique string of four letter alphabet. Letters A, C, G, and T are chosen, since they are the same as used in DNA sequences. In this way it possible to utilize tools originally programmed to DNA sequences analysis. When all pixel values of frames (images) are converted to virtual DNA sequences, one can show the differences between two virtual DNA sequences. The comparison between two virtual DNA sequences is done by Chi-squared test, DNA Sequence Alignment Algorithms (Needleman Wunsch and Smith Waterman), Markov Chain and glm plot. The rate of similarity between frames is plotted as a graph and it's appearing in Monitor.

\section{Experiment results}

We performed the experiments a real video data sheet. In this experiment we selected 15 different frame images from the same video data sheet. The goal is to find correspondences between similar sub images. Similarity is defined in terms of DNA Modeling and images are represented by sequences trees that capture sequence times. The range of similarity scores is defined as a set of variable of plot. Generally, practical framework of Morbid Motion Monitor involves the following:

\section{Data collection}

Primarily, data is collected to provide information regarding morbid motion on the bedside. The step is executed by video camera. The sleep walking dog is an example in our experiment.

\section{Real video data sheet}

Video data is formulated for use in the reference archive of images.

\section{Plotting the similarity score}

The similarity score between the two aligned sequence sheets (images) over the entire video are plotted at the position of the monitor.

\section{Discussion}

Morbid Motion Monitory system could be widely used to access level of consciousness and neurological scales e.g. Glasgow Coma Scale. In this study we will target validation of the Morbid Motion Monitor Pain Scale in the Finnish population.

\section{Conclusion}

The system is used to show and describe the displacement of the morbid on the bedside. The amount of ill transmitted to the morbid increase the motion ratio. In this manner Motion Ration is the ratio of the displacement of the morbid.

\section{References}

1. Scholz J, Mannion RJ, Hord DE, Griffin RS, Rawal B, et al. (2009) A Novel Tool for the Assessment of Pain: Validation in Low Back Pain. PLoS Med 6(4): e1000047.

2. Sun V, Borneman T, Piper B, Koczywas M, Ferrell B (2008) Barriers to pain assessment and management in cancer survivorship. J Cancer Surviv 2(1): 65-71.

3. Bennett M (2001) The LANSS Pain Scale: the Leeds assessment of neuropathic symptoms and signs. Pain 92(1-2): 147-157.

4. Krause SJ, Backonja MM (2003) Development of a Neuropathic Pain Questionnaire. Clin J Pain 19(5): 306-314.

5. Santos JG, Brito JO, de Andrade DC, Kaziyama VM, Ferreira KA, et al (2010) Translation to Portuguese and Validation of the Douleur Neuropathique 4 Questionnaire. J Pain 11(5): 484-490.

6. Howard Smith (2009) Current Therapy in Pain. pp. 1-704.

7. Freynhagen R, Baron R, Gockel U, Tölle TR (2006) Pain DETECT: a new screening questionnaire to identify neuropathic components in patients with back pain. Curr Med Res Opin 22(10): 1911-1920. 
8. Bennett MI, Attal N, Backonja MM, Baron R, Bouhassira D, et al. (2007) Thomas R Tölle, Hans-Ulrich Wittchen, Troels Staehelin Jensen (Eds,).
Using screening tools to identify neuropathic pain. Pain 127(3): 199203.

Your next submission with Juniper Publishers
will reach you the below assets
- Quality Editorial service
- Swift Peer Review
- Reprints availability
- E-prints Service
- Manuscript Podcast for convenient understanding
- Global attainment for your research
- Manuscript accessibility in different formats
( Pdf, E-pub, Full Text, Audio)
- Unceasing customer service
Track the below URL for one-step submission
https://juniperpublishers.com/online-submission.php

